\title{
Extraction of Chemical Constituents of Bitumen Using a Mixed Solvent System
}

\author{
Ezekiel Oluyemi Odebunmi', Abimbola George Olaremu2* \\ ${ }^{1}$ Department of Chemistry, University of Ilorin, Ilorin, Nigeria \\ ${ }^{2}$ Department of Chemical Sciences, Adekunle Ajasin University, Akungba Akoko, Nigeria \\ Email: ${ }^{*}$ abimbolaremu@yahoo.com
}

Received 21 July 2015; accepted 21 August 2015; published 24 August 2015

Copyright (C) 2015 by authors and Scientific Research Publishing Inc.

This work is licensed under the Creative Commons Attribution International License (CC BY). http://creativecommons.org/licenses/by/4.0/

(c) (i) Open Access

\begin{abstract}
Several solvents had been used to extract the SARA (Saturate, Aromatic, Resin and Asphaltene) constituents of bitumen. The quantification of such extracts also abounds in open literature but in this work an attempt was made to determine the quality of extraction as a feed stock for processing bitumen using a mixed solvent system. A mixture of heptane and toluene was used to compare with the standard method using heptane. The components were analysed for functional groups of compound types presented in them using Fourier Transform Infrared Spectrophotometry technique (FTIR). The quality of bitumen component extract was not significantly affected by the method of extraction as recommended by the ASTM. The components are mixture of different class of hydrocarbons such as saturated and unsaturated hydrocarbons which conformed to what had earlier been reported by other researchers.
\end{abstract}

\section{Keywords}

Bitumen, Sara, Ftir, Solvent System

\section{Introduction}

Bitumen is a complex mixture, containing a high proportion of poorly soluble asphaltenes. Unpredictable precipitation of this component can cause process problems during bitumen extraction. Consequently, the selection of an appropriate solvent is an important factor in the optimization of bitumen separation by solvent extraction [1]. Bitumen can be gotten as one of the fractions from distillation of crude oil or oil sands. The oils sands extraction process is composed of an extraction step and a characterization step. The first step is the extraction with heated toluene into three components; bitumen, solid content (sand and clay) and water [2].

"Corresponding author.

How to cite this paper: Odebunmi, E.O. and Olaremu, A.G. (2015) Extraction of Chemical Constituents of Bitumen Using a Mixed Solvent System. Open Journal of Applied Sciences, 5, 485-494. http://dx.doi.org/10.4236/ojapps.2015.58047 
The second step is the characterization of bitumen to determine the asphaltene content in the bitumen. Asphaltene is a low value added product present in the bitumen. The higher the asphaltene content, the lower the value of the bitumen [3]. Figure 1 shows the use of an adsorbent to fractionate the deasphaltened oil [4].

Bitumen comprises three main components, namely, maltenes, resins and asphaltenes. Whereas maltenes are infinitely soluble in paraffinic solvents, and the complete dissolution of resins and asphaltenes requires the use of relatively polar, aromatic solvents, such as benzene or toluene. In conventional practice, asphaltenes are separated from maltenes by adding a large excess of pentane to a solution of bitumen in benzene. However, the solubility of asphaltenes in paraffins increases in proportion to the number of carbon atoms in the solvent and this provides a means of fractionating asphaltenes on the basis of their molecular weight. The selected bitumen solvent must therefore have the proper balance between paraffinic and aromatic components [1].

Considerable research has been performed in an effort to separate bitumen from oil sands using solvent extraction [5] [6]. Several process were suggested to slurry the oil sands in one or multiple non-aqueous solvents followed by filtration and then separation of the solvent from the sand tailings [7] [8].

Hanson et al. investigated a solvent extraction process using aromatic hydrocarbons, such as toluene, which included extraction, separation, drying, and solvent recovery, and achieved the circulation of solvent with less environmental impact [9]. However, the major problems of the process are its complexity and high energy consumption. To overcome the high solvent loss and energy consumption of the non-aqueous extraction process, Gantz and Hellwege patented the use of trichloroethylene as a solvent in conjunction with a small amount of a surfactant [10].

Leung and Phillips investigated the use of benzene, toluene, and kerosene as the solvent, and they observed higher mass transfer rates when using solvents with higher aromaticity or lower boiling points [11]. For largescale operation, the solvents must be easy to recover from the extraction gangue.

Consequently, solvents, such as naphtha and kerosene, can be ruled out. Furthermore, despite their effectiveness in dissolving bitumen, the aromatic solvents are unsuitable because of odor and toxicity.

Sparks and Meadus studied solvent extraction by naphtha as a solvent followed by spherical agglomeration of extracted sands by adding water. Water phase replaced solvents phase in the agglomerates, and agglomerates were separated from the solvent by screening. The optimum added water to sand ratio depended on the fines content of the oil sands but was around 0.13 . Bitumen recovery in this process reached $95 \%$, and naphtha content of the extracted sands decreased to around 3\% [12] [13].

Wu and Dabros studied the non-aqueous extraction of bitumen by light hydrocarbon solvents followed by centrifuge filtration or regular filtration. The solvent was recovered from flirtation cake by vacuum evaporation at room temperature. They studied different solvents, n-pentane, hexane, cyclopentane, a mixture of n-pentane

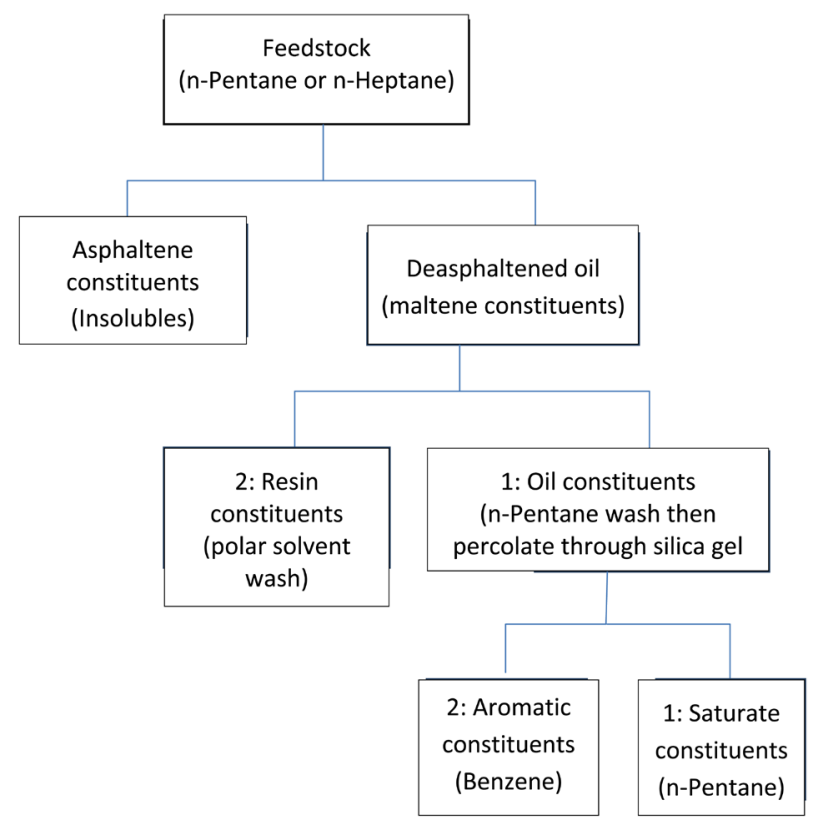

Figure 1. The ASTM D2007 Fractionation procedure. 
and cyclopentane and toluene, and suggested cyclopentane as the best solvent. Bitumen recovery using cyclopentane as the solvent reached $90 \%$ by a single stage extraction at a solvent to bitumen ratio of over 4 . By a three-stage extraction, the bitumen recovery can reach above 95\% using a solvent to bitumen ratio of 1 . Using pressure filtration instead of centrifuge filtration showed lower bitumen recoveries. The residual solvent content in the extracted oil sands tailings was the lowest for n-pentane and cyclopentane, which have the lowest boiling points among the tested solvents. The residual solvent content for cyclopentane after 20 min vacuum drying was $0.4 \%$ of the extracted bitumen or $550 \mathrm{mg} / \mathrm{kg}$ in the extraction tailings [14].

Studies by Hooshiar et al. [15] and Nikakhtari et al. [16] [17] found that bitumen recovery was over 95\% for a range of ore grades and solvent blends. Nikakhtari and fellow workers thus, recommended cyclohexane as a potential solvent for bitumen extraction based on high bitumen recovery, low fine solids in the produced bitumen, and rapid evaporation of cyclohexane from the gangue. They found that the migration of fine solids into the product bitumen was very sensitive to the solvent properties, suggesting that choosing a proper solvent blend could control the behavior of these solids. In addition, unlike laboratory reagents, potential low-cost industrial solvents will not be pure but will consist of a mixture of related compounds.

Investigations were conducted by Krupal to evaluate the performance of solvent mixtures to extract bitumen from a high-grade oil sands ore. Solvent mixtures of cycloalkane and n-alkanes were studied on the basis of their Hildebrand solubility parameters, which affect bitumen recovery and fine solids migration during the extraction process, and the results were compared to single solvents. Cyclohexane, cyclopentane, and methylcyclopentane were selected as the cycloalkane solvents, and they were studied in combination with n-alkane solvents, such as n-heptane, n-hexane, or n-pentane, to make up a final solubility parameter between 16.65 and $16.45 \mathrm{MPa} 1 / 2$ for the final solvent mixture. It was observed that the solubility parameter of the solvent mixture has more impact on the migration of fine solids in bitumen than the recovery of bitumen. The amount of fine solids migrating into the bitumen product followed the order of cycloalkane/n-heptane > cycloalkane/n-hexane > cycloalkane/n-pentane [18]. However, the effect of the mixture on the chemical nature of the SARA component had never been reported in any open literature. The aim of this research therefore is to compare the chemical nature of the extracted constituents to determine if the method of extraction or separation using different solvent systems has any major effect on the SARA constituents and using bitumen sources from Nigeria as our feedstock.

\section{Materials and Method}

\subsection{Collection of Samples}

Bituminous sand samples were collected from Agbabu, in Ondo State, Southwest Nigeria (Figure 2), by scooping the viscous bituminous sand samples into air light plastic containers and conveying the samples immediately to the laboratory for processing and analysis.

All solvents were double distilled analytical grade. The adsorbent was (supplied by Heloatta, Akure, Nigeria) was activated in a muffle furnace at $600^{\circ} \mathrm{C}$ for 6 hours. The chromatographic column tubing of $1 \mathrm{~m}$ long and $0.04 \mathrm{~m}$ internal diameter was constructed in Federal University of Technology Akure, Ondo state.

\subsection{Determination of Asphaltene and Raffinate Components of Bitumen}

A modified ASTM-2007 method was used as follows. A mixture of 50/50vol\% heptane/toluene in the modified method instead of $100 \mathrm{vol} \%$ heptane or pentane in the standard method. Exactly $200 \mathrm{ml}$ n-heptane/toluene mixture was added to $20 \mathrm{~g}$ of bitumen in an Erlenmeyer flask. This was refluxed at $98^{\circ} \mathrm{C}$ for about 6 hours. After cooling, the extract was decanted into another flask, the residue left was thoroughly rinsed with n-heptane/toluene into the second flask containing the extract and pure residue was taken as asphaltene while the extract was taken as raffinate after solvent removal using rotary evaporator. The procedure was repeated with $100 \mathrm{vol} \%$ heptane in the standard method

\subsection{Column Chromatographic Fractionation of Raffinate into Oil and Resins}

A chromatographic column was carefully and neatly packed with activated neutral alumina after pre-wetting with n-heptane. The raffinate was introduced into the column after dissolution in $100 \mathrm{ml}$ n-heptane. The oil component being the least polar came out first as expected, the process continued with more n-heptane being added until n-heptane coming out was colourless. The remaining resins were progressively eluted with increasing polar 


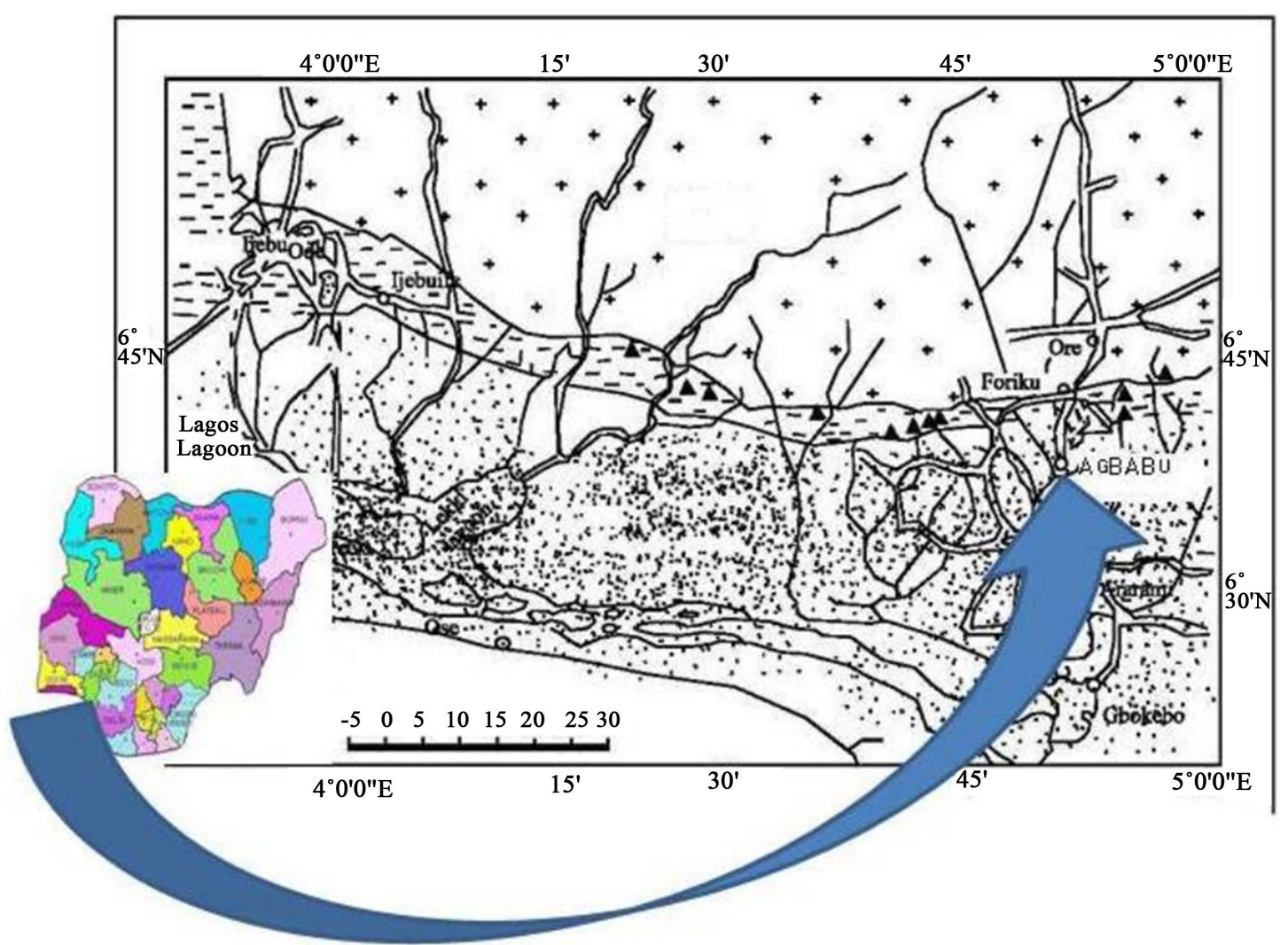

Figure 2. Showing the location of our sample collection [19].

solvents; toluene, trichloromethane and ethanol until solvent coming out in each elusion were colourless. The eluents were recovered from the bitumen components by rotary evaporation [20].

\subsection{Structural Characterization by Fourier Transform Infrared (FTIR)-Spectroscopy}

The bitumen components (asphaltene, oil, and resins) were investigated for functional assignment by infrared spectroscopy using a Shimadzu FTIR-8300 spectrometer. The spectra of the homogenized material, in the form of $\mathrm{KBr}$ discs, were analysed in the range of 400 to $4000 \mathrm{~cm}^{-1}$.

\subsection{Atomic Absorption Spectroscope (AAS) Determination of Trace Metal Contents in Bitumen Components}

Sample preparation for analysis was done by dry ashing and dissolution of the ash in mineral acids [21]. Duplicate of $1 \mathrm{~g}$ sample of oil component contained in crucibles with lids was placed in a furnace maintained at $500^{\circ} \mathrm{C}$ for 5 hours. $1 \mathrm{~mL}$ of $2 \mathrm{M} \mathrm{HCI}$ was added to the ashed sample in the crucible and allowed to boil to dryness on a water bath. After drying, another batch of $1 \mathrm{~mL} 2 \mathrm{M}$ HCI was added, but left to boil only for few minutes before being transferred into $50 \mathrm{ml}$ volumetric flask. The crucible was rinsed several times with double distilled water into this flask and made up to the graduating mark with double distilled water. The solution was subjected to AAS analysis using the Bulk model 200 A Atomic Absorption Spectrophotometer to determine the presence and concentration of metals.

\section{Results and Discussion}

The saturate (Oil) components of the Agbabu bitumen are $36.80 \%$ and 36.20 for the standard method and the modified method respectively. These values are greater than most of the values reported by some researchers [19] [22] [23] but the discrepancy is not significant. The values obtained in the standard method corresponds to what 
was reported by Oderinde and Olanipekun [24]; Adebiyi and Omode [20], however, the values are less than the 51.5\% and 39.6\% reported by Ells [25] for the oil components of the Alberta and Bermudez respectively.

The Nigerian bitumen is richer in the saturates (oil) components than the Athabasca and Cold lake bitumen [26] and a number of Chinese and Middle Eastern vacuum resids reported by Liu et al. [27].

The functional group assignment for the bitumen components using standard and the modified method is presented in Tables 1-5, while the IR spectrum of four (as a representation) of the samples are presented in Figures 3-6.

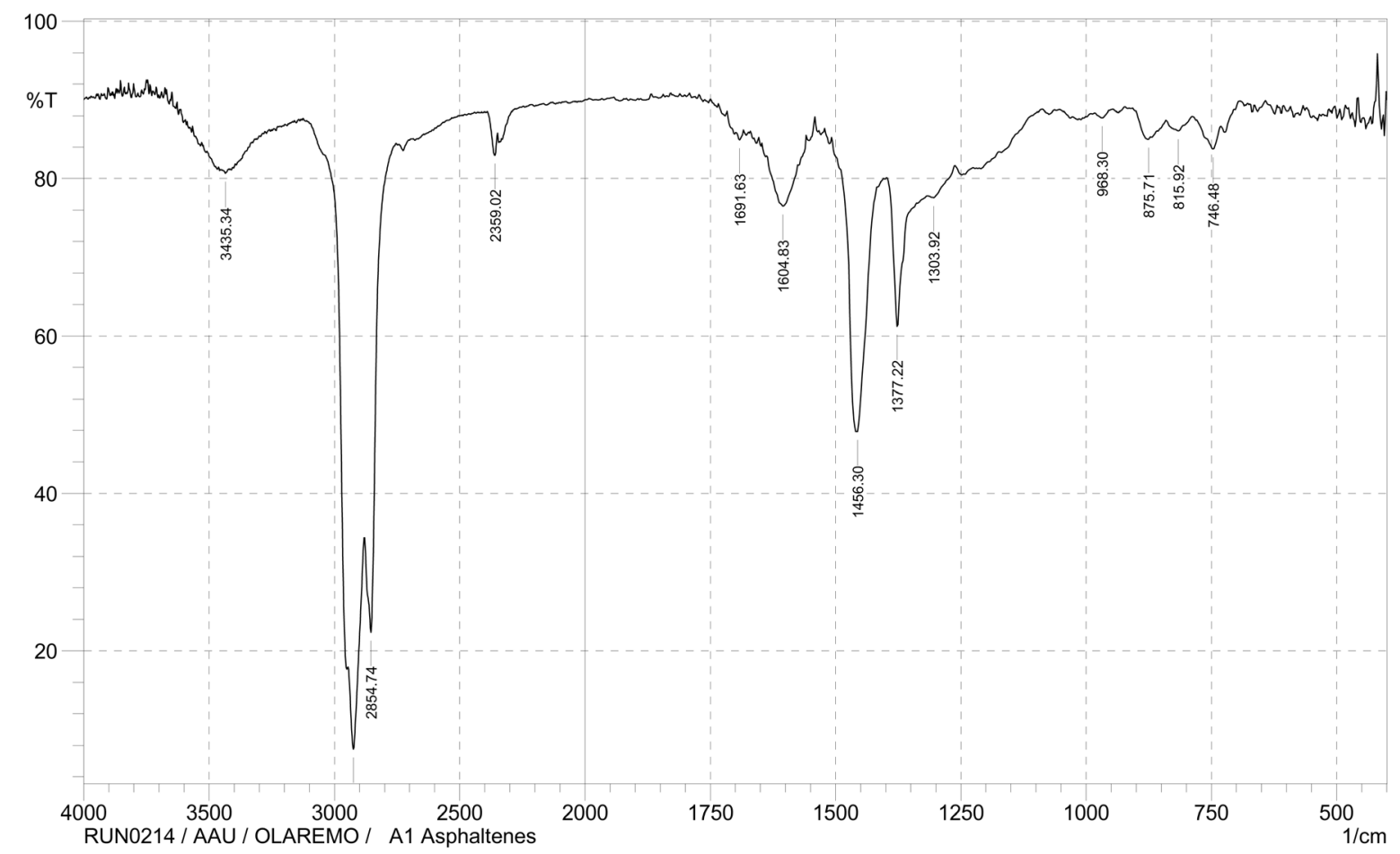

Figure 3. FTIR Spectra for SARA (Asphatene) extraction with 50\% Heptane, 50\% Toluene.

Table 1. Comparation of FTIR peaks of Asphaltene.

\begin{tabular}{ccc}
\hline $50 \%$ Heptane, $50 \%$ Toluene & $100 \%$ Heptane & Functional Group \\
746.48 & 669.32 & Aliphatic Halogen compounds \\
815.92 & 746.48 & Aromatic \\
875.71 & 883.43 & Aromatic \\
968.3 & & Aromatic \\
1303.92 & 1303.92 & Alkanes \\
1377.22 & 1377.22 & Aromatic amines \\
1456.3 & 1458.23 & Organic sulfates \\
1604.83 & 1610.61 & Alkanes \\
1691.63 & 1697.41 & Carbonyls \\
2359.02 & 2360.95 & Carboxylic acid \\
2854.74 & 2854.74 & Si-H, Thio/Sulfides, Phosphines, Arsines, Borones \\
2924.18 & 2924.18 & Alkane \\
3435.34 & 3437.26 & Alkane \\
\hline
\end{tabular}




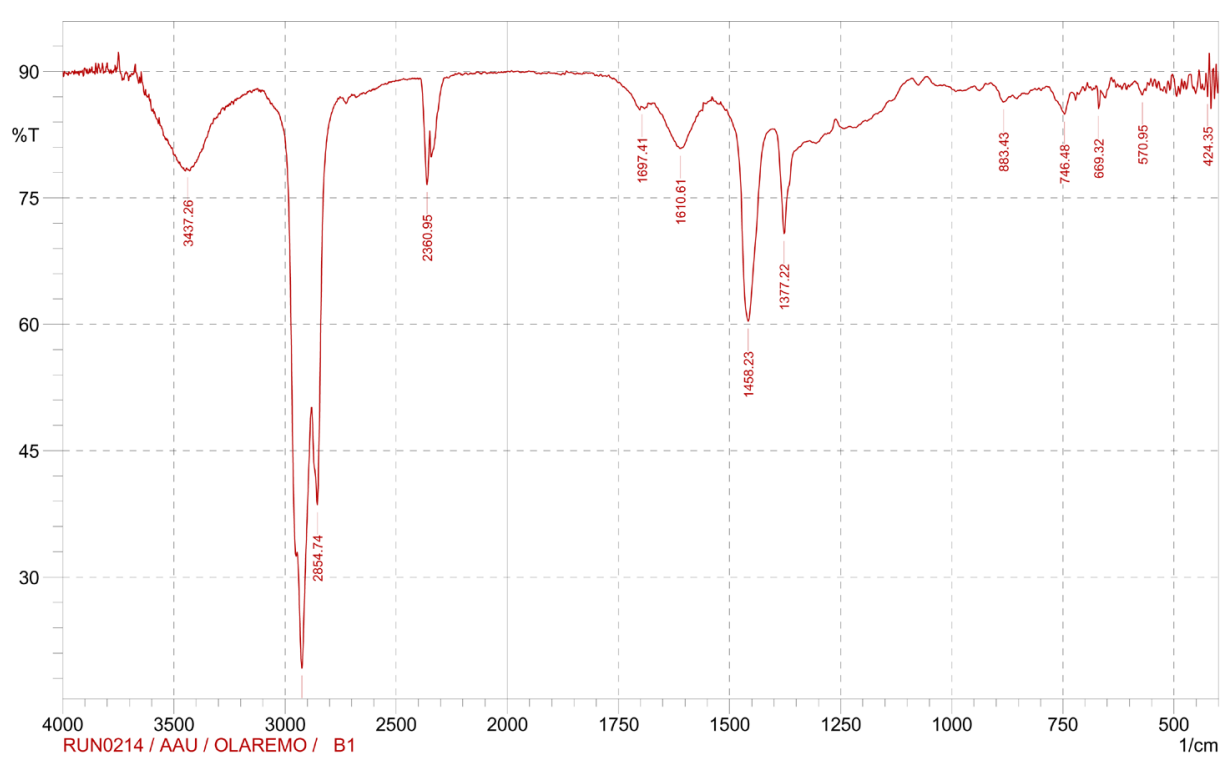

Figure 4. FTIR Spectra for SARA (Asphatene) extraction with 100\% Heptane.

Table 2. Comparation of FTIR peaks of Heptane extract.

\begin{tabular}{|c|c|c|}
\hline 50\% Heptane, 50\% Toluene & 100\% Heptane & Vibrational response \\
\hline 653.89 & 669.32 & Alkyl halides \\
\hline 721.4 & 744.55 & Aromatics \\
\hline 854.49 & 875.71 & Aromatics \\
\hline 1298.14 & & Alkyl halides \\
\hline 1377.22 & 1377.22 & Organo sulfate \\
\hline 1458.23 & & Alkanes \\
\hline 1608.69 & 1612.54 & Primary amine \\
\hline 2360.95 & 2359.02 & Si-H, Thio/Sulfides, Phosphines, Arsines, Borones \\
\hline 2854.74 & 2854.74 & Alkane \\
\hline 2924.19 & 2924.18 & Alkane \\
\hline 3425.69 & 3439.19 & Alcohols, Phenols \\
\hline 50\% Heptane, 50\% Toluene & 100\% Heptane & Vibrational response \\
\hline 744.55 & 746.48 & Aromatic \\
\hline 815.92 & & Aromatic \\
\hline 875.71 & 881.5 & Aromatic \\
\hline 1031.95 & 1030.7 & Aliphatic amines \\
\hline 1305.85 & 1305.85 & Aromatic amines \\
\hline 1377.22 & 1377.22 & Organo sulfates \\
\hline 1456.3 & 1458.23 & Alkanes \\
\hline 1602.9 & 1608.69 & Alkanes \\
\hline 1695.49 & 1697.41 & Carboxylic acid \\
\hline & 2359.02 & Si-H, Thio/Sulfides, Phosphines, Arsines, Borones \\
\hline 2852.81 & 2852.81 & Alkane \\
\hline 2924.18 & 2924.18 & Alkane \\
\hline & 2951.19 & Alkane \\
\hline 3435.34 & 3435.34 & Alcohols, Phenols \\
\hline
\end{tabular}




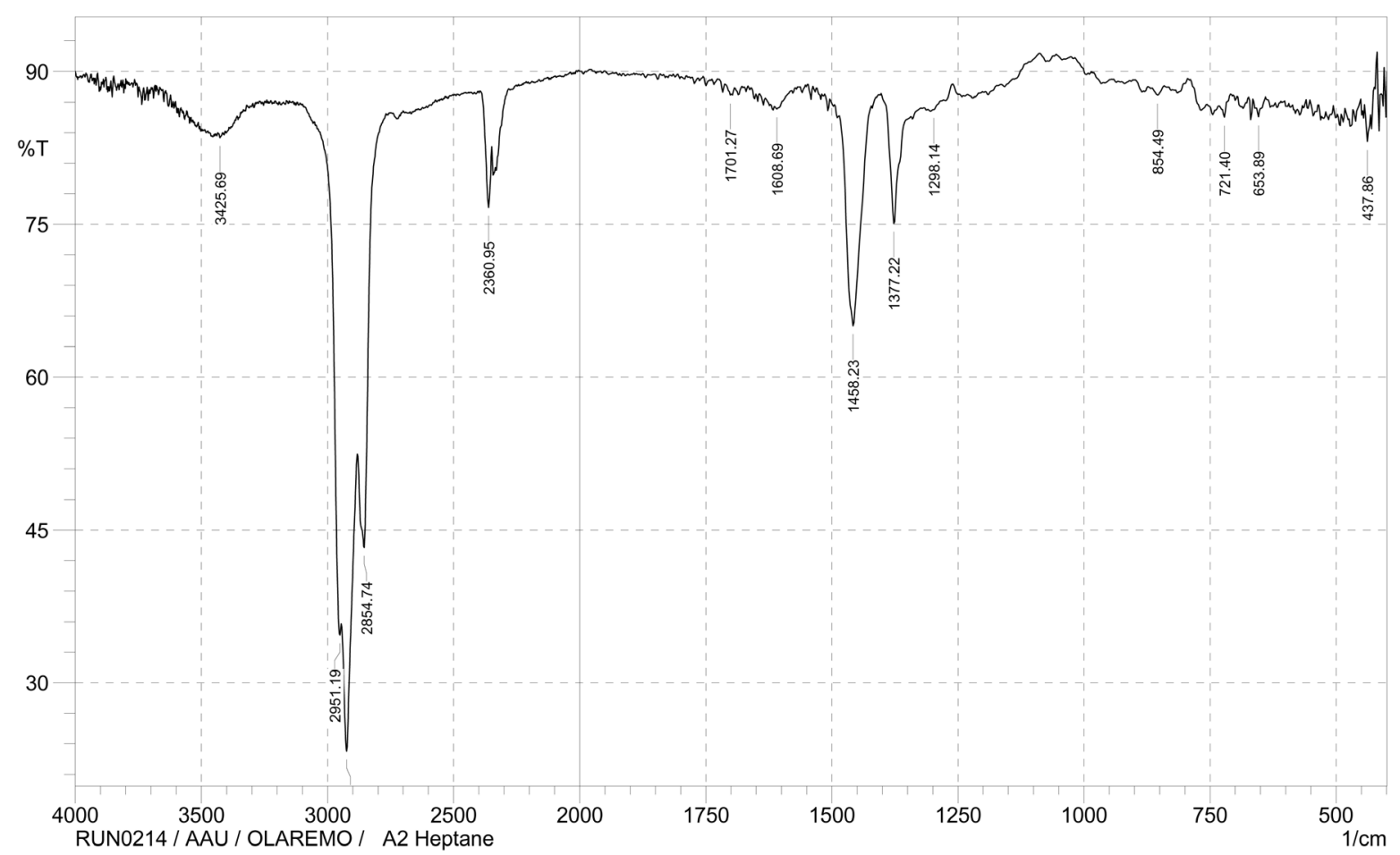

Figure 5. FTIR Spectra for SARA extraction (Oil) with 50\% Heptane, 50\% Toluene.

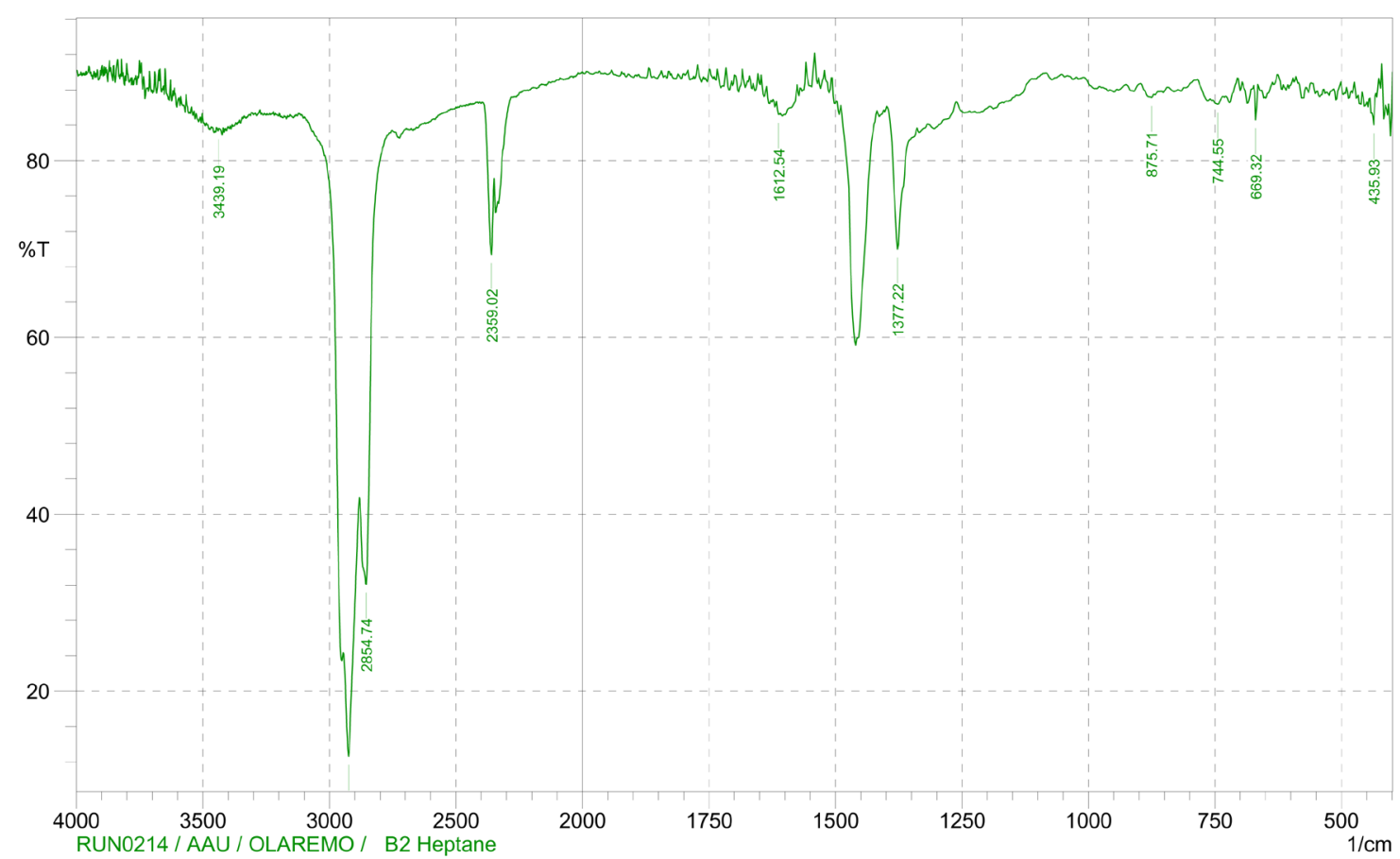

Figure 6. FTIR Spectra for SARA (Oil) extraction with 100\% Heptane.

Saturated hydrocarbon and aromatic compounds are present in all the components separated indicating the high quality of the Nigerian bitumen in agreement with the previous work of Adebiyi and Omode [20]; Moschopedis et al. [28] that reported more hydrocarbons (oil) that are saturates and aromatics which can be generated from the pyrolysis of asphaltene at $300^{\circ} \mathrm{C}-350^{\circ} \mathrm{C}$. 
Table 4. Comparation of FTIR peaks of Ethanol extract.

\begin{tabular}{ccc}
\hline $50 \%$ Heptane, $50 \%$ Toluene & $100 \%$ Heptane & Vibrational response \\
\hline 542.02 & 540.34 & Alkyl halide \\
744.55 & 721.4 & Aromatic \\
1010.73 & 1012.66 & Alcohols, carboxylic acids, esters, ethers \\
1377.22 & 1377.22 & Organic sulfate \\
1458.23 & 1460.16 & Alkanes \\
1604.83 & 1604.83 & Primary amines \\
& 1658.84 & Alkanes \\
1707.06 & 1705.13 & Carboxylic acid \\
2366.74 & 2360.95 & Alkane \\
2854.74 & 2854.74 & Alkane \\
2924.18 & 2924.18 & Al-H, Thio/Sulfides, Phosphines, Arsines, Borones \\
2953.12 & & Alcohols, Phenols \\
3443.05 & 3431.48 & \\
\hline
\end{tabular}

Table 5. Comparation of FTIR peaks of Chloroform extract.

\begin{tabular}{ccc}
\hline $50 \%$ Heptane, $50 \%$ Toluene & $100 \%$ Heptane & Vibrational response \\
\hline 721.4 & 721.4 & Aromatics \\
& 827.49 & Aromatics \\
1080.3 & 966.37 & Alkenes \\
1186.26 & 1080.17 & Aliphatic Amine \\
1290.42 & 1188.19 & Alkyl halides \\
1377.22 & 1288.49 & Alkyl halides \\
1460.16 & 1377.22 & Organic sulfate \\
1707.06 & 1464.02 & Alkanes \\
2360.95 & 1707.06 & Carboxylic acid \\
2852.81 & 2854.74 & Si-H, Thio/Sulfides, Phosphines, Arsines, Borones \\
2924.18 & 2924.18 & Alkane \\
2955.04 & & Alkane \\
3433.41 & 3425.69 & Alkane \\
\hline
\end{tabular}

In the current investigation, the presence of different class of hydrocarbon discovered in all the components conformed to the earlier report by various researches on studies on Nigerian bitumen. Worthy of note however is that the quality and components of the hydrocarbon is not affected by the method of extraction whether in the standard or modified method.

Table 6 below compares the results obtained in this work for the oil components of Nigerian bitumen with previous reports as detailed in the table. 
Table 6. Average trace metal concentrations of Nigerian bitumen, ppm.

\begin{tabular}{ccccc}
\hline Metal & Obiajunwa and Nwachukwa 2000 [29] & Ipinmoroti and Aiyesanmi 2001 [30] & Adebiyi and Omode 2007 [20] & Present study \\
\hline $\mathrm{Zn}$ & 119.00 & 7.00 & 100.94 & 120.00 \\
$\mathrm{Ni}$ & $\mathrm{NDT}$ & 21.00 & 20.22 & 11.20 \\
$\mathrm{Cu}$ & 72.00 & BDL & ND & ND \\
$\mathrm{Pb}$ & 69 & 80.00 & 57.49 & 12.68 \\
$\mathrm{~V}$ & $\mathrm{NDT}$ & 37.00 & 7.59 & 13.80 \\
$\mathrm{Fe}$ & $48,300.00$ & 234.00 & 204.93 & 210.44 \\
$\mathrm{Mn}$ & 216.00 & NDT & 12.41 & 11.67 \\
\hline
\end{tabular}

NDT: not determined, BDL: below detection limits (0.02 ppm for Cu).

The understanding of the metals present in bitumen is very important as they have effect during thermal and catalytic processing [31]-[37]. Metals during catalytic upgrading cause catalyst poisoning and deactivation.

\section{Conclusion}

The quality of bitumen component extracted is not significantly affected by the method of extraction as recommended by the ASTM 2007. Nigeria bitumen was used to test run this hypothesis and was observed to be true. From our results, the components are mixture of different classes of hydrocarbon hence; the bitumen is a huge reservoir of petrochemicals which can be vital for the chemical industry development.

\section{Acknowledgements}

The authors are grateful to TETFUND and Adekunle Ajasin University Akungba Akoko for supporting the postgraduate studies of Mr. Olaremu, A.G. We also which to appreciate the technologies at the department of Chemistry, University of Ilorin and the Department of Chemical Sciences Adekunle Ajasin University, Akungba Akoko for their assistance during the period of this research.

\section{References}

[1] Sparks, B.D., Meadus, F.W., Kumar, A. and Woods, J.R. (1992) The Effect of Asphaltene Content on Solvent Selection for Bitumen Extraction by the SESA Process. Fuel, 71, 1350-1353. http://dx.doi.org/10.1016/0016-2361(92)90205-3

[2] Kettle, A. and Voelker, P. (2014) Accelerated Solvent Extraction for Bitumen Extraction from Oil Sands. Thermo Fisher Scientific, Sunnyvale. www.thermoscintific.com/dionex

[3] Petroleum Technology Alliance Canada (2014) Oil Sands. (Online) http://www.ptac.org/projects/59

[4] Speight, J.G. (2006) Chap. 8: The Chemistry and Technology of Petroleum. 4th Edition, CRC press, USA, 263.

[5] Coulson, G.R. (1958) Process for Separation Oil from Bitumenous Sands, Shales, Etc. US Patent No. 2,825,677.

[6] Wang, T., Zhang, C., Zhao, R.Y., Zhu, C.J., Yang, C.H. and Liu, C.G. (2014) Solvent Extraction of Bitumen from Oil Sands. Energy Fuel, 28, 2297-2304. http://dx.doi.org/10.1021/ef402101s

[7] Leary, T.S. and Cottrell, J.H. (1964) Recovery of Bitumen from Bitumenous Sand. US Patent No. 3,117,922.

[8] Benson, A.M. (1969) Filtration of Solvent-Water Extracted Tar Sand. US Patent No. 3,459,653.

[9] Hanson, D.O. and Sherk, F.T. (1979) Solvent Extraction of Tar Sand. US Patent 4,139,450.

[10] Gantz, D.E. and Hellwege, J.W. (1977) Solvent Extraction of Oil from Tar Sands Utilizing a Trichloroethylene Solvent. US Patent No. 4,046,669.

[11] Leung, H. and Phillip, C.R. (1985) Solvent Extraction of Mined Athabasca Oil Sands. Industrial \& Engineering Chemistry Fundamentals, 24, 373-379. http://dx.doi.org/10.1021/i100019a015

[12] Sparks, B.D. and Meadus, F.W. (1988) Solvent Extraction Spherical Agglomeration of Oil Sands. US Patent No. 4,719,008.

[13] Sparks, B.D. and Meadus, F.W. (1979) A Combined Solvent Extraction and Agglomeration Technique for the Recovery of Bitumen from Tar Sand. Energy Processes Canada, 72, 55-61. 
[14] Wu, J. and Dabros, T. (2012) Process for Solvent Extraction of Bitumen from Oil Sand. Energy \& Fuels, 26, 10021008. http://dx.doi.org/10.1021/ef201457m

[15] Hooshiar, A., Uhlik, P., Liu, Q., Etsell, T.H. and Ivey, D.G. (2012) Clay Minerals in Nonaqueous Extraction of Bitumen from Alberta Oil Sands. Fuel Processing Technology, 94, 80-85. http://dx.doi.org/10.1016/j.fuproc.2011.10.008

[16] Nikakhtari, H., Vagi, L., Choi, P., Liu, Q. and Gray, M.R. (2013) Solvent Screening for Non-Aqueous Extraction of Alberta Oil Sands. The Canadian Journal of Chemical Engineering, 91, 1153-1160. http://dx.doi.org/10.1002/cjce.21751

[17] Nikakhtari, H., Wolf, S., Choi, P., Liu, Q. and Gray, M.R. (2014) Migration of Fine Solids into Product Bitumen from Solvent Extraction of Alberta Oil Sands. Energy \& Fuels, 28, 2925-2932. http://dx.doi.org/10.1021/ef500021y

[18] Pal, K., da Paz Nogueira Branco, L., Heintz, A., Choi, P., Liu, Q., Seidl, P.R. and Gray, M.R. (2015) Performance of Solvent Mixture for Non-Aqueous Extraction of Alberta Oil Sands. Energy \& Fuels, 15, 2261-2267. http://dx.doi.org/10.1021/ef502882c

[19] Adegoke, O.S and Ibe, E.S. (1982) The Tar Sands and Heavy Crude Resources of Nigeria. Proceedings of 2nd International Conference on Heavy Crude and Tar Sands, Caracas, 1982, 280-285.

[20] Adebiyi, F.A. and Omode, A.A. (2007) Organic, Chemical and Elemental Characterization of Components of Nigerian Bituminous Sands Bitumen.

[21] Association of Official Analytical Chemists (1980) Report of Subcommittee A on Recommendation for Official Methods. Journal of the Association of Official Analytical Chemists, 63, 2.

[22] Ekwezor, C.M. (1985) Nigerian Tar Sands, Bitumen Chemical Properties and Their Application to Origin, Production, and Processing. Proceedings of the 21st Annual Conference of Nigerian Mining and Geosciences Society, Jos, 11-15 March 1985, 26-40.

[23] Oshinowo, T.A.B. and Adediran, A.S. (I982) Bituminous Tar Sands of Nigeria. Journal of the Nigerian Society of Chemical Engineering, 1, 44-48.

[24] Oderinde, R.A. and Olanipekun, E.O. (1990) Composition Analysis of the Oil Component of the Nigerian Bitumen. Journal of African Earth Sciences, 12, 453-487.

[25] Ells, E.C. (1914) Preliminary Report on the Bituminous Sands of Northern Alberta. Canada Department of Mines, Report 281, 86-90.

[26] Clarke, P. and Pruden, B. (1998) Asphaltene Precipitation from Cold Lake and Athabasca Bitumen. Petroleum Science and Technology, 16, 287-305. http://dx.doi.org/10.1080/10916469808949784

[27] Liu, C., Zhu, C., Jin, L., Shen, R. and Liang, W. (1999) Step by Step Modeling for Thermal Reactivities and Chemical Compositions of Vacuum Residues and Their SFEF Asphalt. Fuel Processing Technology, 59, 51-67. http://dx.doi.org/10.1016/S0378-3820(99)00010-7

[28] Moschopedis, S.E., Hawkin, R.W. and Speight, J.G. (1981) Identification of Nitrogen Functional Groups in Athabasca Bitumen. Fuel, 60, 397-400. http://dx.doi.org/10.1016/0016-2361(81)90276-3

[29] Obiajunwa, E.I. and Nwachukwu, J.I. (2000) Simultaneous PIXE and PIGME Analysis of a Nigerian Tar Sand Sample from a Deep Borehole. Journal of Radioanalytical and Nuclear Chemistry, 245, 659-661. http://dx.doi.org/10.1023/A:1006710722339

[30] Ipinmoroti, K.O. and Aiyesanmi, A.F. (2001) Trace Metals in the Bituminous Sands of Ondo State, Nigeria. Nigerian Journal of Science, 35, 63-68.

[31] Chung, K.H., Xu, C., Hu, Y. and Wang, R. (1997) Supercritical Fluid Extraction Reveals Resid Properties. Oil \& Gas Journal, 95, 66-69.

[32] Pearson, C.D. and Green, J.B. (1989) Comparison of Processing Characteristics of Mayan and Wilmington Heavy Residues. 2. Characterization of Vanadium and Nickel Complexes in Acid-Base-Neutral Fractions. Fuel, 68, 456-464. http://dx.doi.org/10.1016/0016-2361(89)90267-6

[33] Speight, J.G. (1990) Fuel Science and Technology Handbook. Chap. 3, Marcel Dekker, New York, 80.

[34] Quann, R.J. and Ware, R.A. (1988) Catalytic Hydrodemetallation of Petroleum. Advances in Chemical Engineering, 14, 95-259. http://dx.doi.org/10.1016/S0065-2377(08)60101-5

[35] Franceskin, P.J., Gonzalez-Jiminez, M.G., Darosa, F., Adams, O. and Katan, L. (1986) First Observation of an Iron Porphyrin in Heavy Crude Oil. Hyperfine Interactions, 28, 825-828. http://dx.doi.org/10.1007/BF02061572

[36] Biggs, J.C., Brown, R.J. and Fetzer, W.R. (1987) Elemental Profiles of Hydrocarbon Materials by Size Exclusion Chromatography/Inductive Coupled Plasma Atomic Emission Spectroscopy. Energy \& Fuels, 1, 257-262. http://dx.doi.org/10.1021/ef00003a006

[37] Ware, R.A. and Wei, J. (1985) Catalytic Hydrodemetallation of Nickel Porphyrins: I. Porphyrin Structure and Reactivity. Journal of Catalysis, 93, 100-121. http://dx.doi.org/10.1016/0021-9517(85)90155-1 